\title{
Retrospective study of central nervous system tumors in the five wars country
}

\author{
Hadeer R Saeed ${ }^{1 *}$, Khudair J Al-Rawaq ${ }^{2}$ and Mohanad F Ibrahim ${ }^{3}$ \\ ${ }^{1}$ Baghdad Radiation Oncology and Nuclear Medicine Center, Iraq \\ ${ }^{2}$ Clinical Radiation Oncology, Department of Surgery, College of Medicine, Baghdad University, Iraq \\ ${ }^{3}$ Department of Neurology, Alkarama Teaching hospital, Baghdad, Iraq
}

\begin{abstract}
Background: CNS tumors constitute $2 \%$ of all cancers and are observed in 4-5 in 100,000.

Aims of study: Detecting the incidence rates of CNS tumors in relation to age, sex, geographical distribution, environmental, and genetic factors. For explaining of the associated clinical features and to determine the effect of radiotherapy, and chemotherapy on the patient's outcome.

Methods: Prospective study of CNS tumors started from the beginning of Jan 2016 to the end of Apr 2016. The study was performed in the outpatient clinic of Oncology Teaching Hospital / Medical City in Baghdad. All patients underwent surgery, chemotherapy and/or radiotherapy, then followed up. The outcome of management was divided into: Good outcome, fair outcome, and poor outcome.

Results: The fifth decade is the most common involved age, with male more than females, and is higher in the south of Iraq. There is little association of CNS tumors with genetic factors, and high association with environmental factors, and smoking. Neurological deficit was the main chief compliant, and headache was present in most of the patients at time of diagnosis. Frontal region was the commonest site for CNS tumors with size of $1-5 \mathrm{~cm}$, and mostly associated with edema and positive enhancement. Meningioma was the commonest histological type.

Conclusions: There is a poor relation between genetic factors and CNS tumors. There is great relation between environmental factors, smoking and CNS tumors. Headache is not the dominant chief compliant. Total resection of the tumor followed by radiotherapy and/or chemotherapy has the best prognosis in patient's outcome.
\end{abstract}

\section{Introduction}

Brain tumor is one of the serious health problem and early diagnosis, awareness of clinical presentation, use proper investigation, many modalities available in treatment chose the proper one in proper time is very important to safe the patient and get survival and disease-free period [1]. CNS tumors constitute $2 \%$ of all cancers and are observed in 4-5 in 100,000 [2]. CNS tumors exhibit different behaviors according to age, histology, and location [1]. Sixty percent of all primary brain tumors are glial tumors, and two-thirds of these are clinically aggressive, high-grade tumors $[1,2]$. Symptoms depend on tumor histology, location, and age. Brain tumors cause neurological disorders by either infiltrating normal CNS structures or obstructing CSF pathways and subsequently increasing intracranial pressure [3]. This increase in intracranial pressure results in the early symptoms of brain tumors: headaches, vomiting and lethargy [3]. $60 \%$ of all primary brain tumors are glial tumors, and two-thirds of these are clinically aggressive, high-grade tumors [1].

\section{Patients and methods}

Retrospective study of CNS tumors started from the beginning of Jan 2016 to the end of Apr 2016 in which a thorough work up of 47 patients were involved. They were taken from the outpatient clinic of Oncology Teaching Hospital / Medical City in Baghdad. All patients proved had brain tumor by histopathological examination. Both sexes involved (26 male and 21 female), and their ages are ranging from (6-73 years). Everyone examined thoroughly and the result were classified, and interpreted according to clinical features and radiological parameters, these includes important signs and symptoms, diagnostic aids with analysis of brain CT and MRI findings, and other diagnostic procedure together with treatment modalities of brain tumor by its different surgical intervention, radiotherapy and chemotherapy. All patients underwent surgery. 42 patients received chemotherapy and/or radiotherapy. RT was done by using $3 \mathrm{D}$ contouring technique by linear accelerator machine. The remaining patients didn't follow up after surgery because they didn't attend to our outpatient's clinic according to their dates of radiotherapy, chemotherapy and follow up visits. The outcome of management was divided into:

\section{Good outcome}

The patients discharge with signs and symptoms better than before management e.g. improvement of hemiparesis or improvement of the level of consciousness.

${ }^{*}$ Correspondence to: Hadeer Riadh Saeed, Baghdad Radiation Oncology and Nuclear Medicine Center, Baghdad Medical City Complex, Ministry of Health/ Environment, Baghdad, Iraq, E-mail; medicalresearch77@yahoo.com

Key words: CNS tumors, Iraq, headache, meningioma

Received: February 27, 2019; Accepted: March 20, 2019; Published: March 29, 2019 


\section{Fair outcome}

The patients after management remain approximately with the same general condition but with no new neurological deterioration.

\section{Poor outcome}

The patients have new neurological deficits or deterioration in general condition.

Statistical analysis was done by using (IBM SPSS v.20) which is a software package used for statistical analysis in addition to the usage of (Microsoft excel 2010) for data sheet collection. The data of all cases were entered and analyzed, then descriptive and analytic statistics were performed using an appropriate statistical configuration (Table 1).

\section{Results}

In this study of 47 patient with brain tumor, the age distribution was as fallow and the peek incidence was in age (40-49) years, male more than female. In family history negative in 39 patients. Study revealed that neurological deficit then the convulsion is most frequent chief complaint. Frontal then parietal is the most common site for diagnosed brain tumor in the study. The size $1-5 \mathrm{~cm}$ were the most frequent. Total resection in the best surgical intervention in relation to outcome even in difficult area or inoperable tumor biopsy remain vital for diagnosis. After surgery histopathology result was glioma is about one third of the sample, while meningioma presented another third and all other histological types in the last third.

\section{Discussion}

In this study the age was from 9-73 years and the mean age was 43 years. The commonest age group was the fifth decade of life (40-49 years), because of the multiple wars in the last 35 years in Iraq, and the exposure to toxic gases, radiations and different chemical materials from bombs, blasts and missiles starting from Iran's war, Kuwait's war, Saddam's fall war and finally the continuous war against terrorist and ISIS till now, we compare our results to other study like Ramandeep et al. [2], which show that $6^{\text {th }}$ decade is the commonest age group. Male is involved in CNS Tumors more than female in our study with male: female ratio 1.23:1. Males were 26 (55.3\%), while females were 21 (44.7\%). This may attribute to genetic factors or more accurately in Iraq due to environmental exposure. When we compare our results to other study as Chang-Hyun et al, [3], the females were involved more than males with the female: male ratio 1.43:1.

Our study shows that the patients with family history were $17 \%$, and those with no history of malignancy were $83 \%$, these were resembling to Quinn et al. [4], that results close to each other, and this improve the poor relation between genetic factors, and CNS tumors.

Our study shown that tobacco smoking observed in 38 (80.8\%) and those ingested alcohol were 9 (19.2\%) of patients.

The results of our study shown that neurological deficit is the commonest chief compliant in $12(25.5 \%)$, followed by convulsions in $11(23.40 \%)$, then headache in $8(17 \%)$. Studies by Hreholz et al. [5] and Louis et al. [6], found that headache was the most common chief compliant and the explanation for this variation is the ignorance of our population to daily headache (considering it as tension headache) and delay in seeking for medical advice until other symptoms like disturb consciousness, convulsions or neurological deficit appears. The same things for nausea and vomiting and others; there is a variation which attributed to sign and symptoms of early increase ICP in the early stage
Table 1. Shown all the study features

\begin{tabular}{|c|c|c|}
\hline Characteristics & & $n(\%)$ \\
\hline \multirow{2}{*}{ Sex } & Male & $26(55.3)$ \\
\hline & Female & $21(44.7)$ \\
\hline \multirow{8}{*}{ Age (years) } & $0-9$ & $1(2.1)$ \\
\hline & $10-19$ & $2(4.3)$ \\
\hline & $20-29$ & $7(14.9)$ \\
\hline & $30-39$ & $9(19.1)$ \\
\hline & $40-49$ & $13(27.7)$ \\
\hline & $50-59$ & $6(12.8)$ \\
\hline & $60-69$ & $7(14.9)$ \\
\hline & $>70$ & $2(4.3)$ \\
\hline \multirow{2}{*}{ Family history } & Positive & $8(17)$ \\
\hline & Negative & $39(83)$ \\
\hline \multirow{2}{*}{ Social habits } & Smoker & $38(80.8)$ \\
\hline & Alcohol & $9(19.2)$ \\
\hline \multirow{8}{*}{ Chief complaint } & Disturb consciousness & $6(12.8)$ \\
\hline & Headache & $8(17)$ \\
\hline & Nausea and vomiting & $4(8.5)$ \\
\hline & Convulsion & $11(23.4)$ \\
\hline & Neurological deficit & $12(25.5)$ \\
\hline & Visual disturbance & $2(4.3)$ \\
\hline & Ataxia & $1(2.1)$ \\
\hline & Mental changes & $3(6.4)$ \\
\hline \multirow{3}{*}{ Surgical procedures } & Biopsy & $3(6.4)$ \\
\hline & Subtotal resection & $21(44.7)$ \\
\hline & Total resection & $23(48.9)$ \\
\hline \multirow{11}{*}{ Histopathology } & Meningioma & $14(29.8)$ \\
\hline & GBM & $9(19.2)$ \\
\hline & Gliomas & $6(12.8)$ \\
\hline & Astrocytoma & $5(10.6)$ \\
\hline & Nerve sheath tumor & $4(8.5)$ \\
\hline & Pituitary tumor & $3(6.4)$ \\
\hline & Oligodendroglioma & $1(2.1)$ \\
\hline & Lymphoma & $1(2.1)$ \\
\hline & Ependymoma & $2(4.3)$ \\
\hline & Embryonal tumor & $1(2.1)$ \\
\hline & Craniopharyngioma & $1(2.1)$ \\
\hline \multirow{8}{*}{ Tumor sites } & Frontal & $11(23.4)$ \\
\hline & Fronto-parietal & $7(14.9)$ \\
\hline & Parietal & $10(21.3)$ \\
\hline & Temporal & $8(17)$ \\
\hline & Parieto-temporal & $3(6.4)$ \\
\hline & Parieto-occipital & $3(6.4)$ \\
\hline & occipital & $3(6.4)$ \\
\hline & Brain stem & $2(4.3)$ \\
\hline \multirow{5}{*}{ Tumor size (cm) } & $<1$ & $9(19.2)$ \\
\hline & $1-5$ & $14(29.8)$ \\
\hline & $5.1-10$ & $8(17)$ \\
\hline & $10.1-20$ & $7(14.9)$ \\
\hline & $>20$ & $9(19.2)$ \\
\hline \multirow{3}{*}{ Treatment modes } & RT & $31(66)$ \\
\hline & Chemoradiation & $11(23.4)$ \\
\hline & Not applicable & $5(10.6)$ \\
\hline \multirow{3}{*}{ Outcome } & Good & $17(36.2)$ \\
\hline & Fair & $22(46.8)$ \\
\hline & Poor & $8(17)$ \\
\hline
\end{tabular}

of the CNS tumors development and because of the delay in diagnosis in our country until late stages when there is high increase in ICP.

Frontal lobe was the major site affected $23.4 \%$, followed by parietal $21.3 \%$, temporal $17 \%$, occipital $6.4 \%$, and then brain stem $4.3 \%$, also 
we found $27.65 \%$ was shared between tow lobes. By look to the study results of Umeo et al. [7], frontal lobe was $17.2 \%$, parietal $8.6 \%$, temporal $26.2 \%$, occipital $3.4 \%$, brain stem $0.8 \%$, and multi-lobes $43.8 \%$.

The highest result for $1-5 \mathrm{~cm}$ tumor size obtained, which dislike of Mark et al. [8], it was 4-6 cm.

The biopsy presented in $6.4 \%$, the subtotal resection $44.7 \%$, and the total resection $48.9 \%$. The total resection is the best one when it is possible because of its better prognosis and survival results. American Brain Tumor Association stated that the most common surgical option is biopsy followed by subtotal resection and then total resection when available [9].

Regarding histopathology meningioma presented in $29.8 \%$, GBM $19.2 \%$, Glioma $12.8 \%$, astrocytoma $10.6 \%$, nerve sheath tumor $8.5 \%$, and pituitary tumor $6.4 \%$. These were similar to that of Alturki et al. [10].

All 31 (66\%) received radiotherapy, 11 (23.4\%) received chemoradiation, and 5 patients $(10.6 \%)$ did not receive any things (because they canceled date of radio or chemotherapy). So the good outcome found in $17(36.2 \%)$, the fair $22(46.8 \%)$, and the poor outcome in $8(17 \%)$ only.

In radiology findings the enhancement presented in $97.9 \%$, followed by edema $91.5 \%$, mid line shift $87.2 \%$, necrosis $80.9 \%$, cystic changes $78.7 \%$, and calcification $10.6 \%$, this is too close to the results of Assari et al. [11].

\section{Conclusions}

There is a poor relationship between genetic factors and CNS tumors because $83 \%$ of the patients in our study had negative family history of malignancy. Males in Iraq more than female affected. According to our results, there is a high association between smoking and CNS tumors. Headache was not $1^{\text {st }}$ chief compliant for CNS tumors in our country. Total resection of the tumor followed by radio and/or chemotherapy has better prognosis in the outcome.

\section{References}

1. Chang AE, Ganz PA, Hayes DF, Kinsella T, Pass HI, et al. (2006) Oncology, an evidence-based approach. Springer 487-488

2. Arora RS, Alston RD, Eden TO, Estlin EJ, Moran A, et al. (2008) Age incidence patterns of primary CNS tumors in children, adolescents, and adults in England, Royal Manchester Children's Hospital. Neuro Oncol 11: 403-413. [Crossref]

3. Lee CH, Jung KW, Yoo H, Park S, Lee SH (2010) Epidemiology of Primary Brain and Central Nervous System Tumors in Korea. J Korean Neurosurg 48: 145-152. [Crossref]

4. Ostrom QT, McCulloh C, Chen Y, Devine K, Wolinsky Y, et al. (2012) Family history of cancer in brain tumor subtypes versus gliomas. Front Oncol 2: 19. [Crossref]

5. Herholz K, Langen KJ, Schiepers C, Mountz JM (2012) Brain tumor. Semin Nucl Med 42: 356-370. [Crossref]

6. Stark AM, Nabavi A, Mehdorn HM, Blömer U (2012) Glioblastoma multiforme-repor of 267 cases treated at a single institution. Surg Neurol 63: 162-169. [Crossref]

7. Umeo I, Alexander B, Konstantin AH (2012) The use of diffusion-weighted MRI to localize tumors without contrast enhancement in glioma, Schwannoma and neuroblastoma. Available from: https://books.google.iq/books?isbn=3709193346

8. Mark SG, Nicolas A, Edward AM (2010) Handbook of Neurosurgery. Tumor. Thieme ( $7^{\text {th }}$ Edn).

9. Assari S, Matayama S, Itoh T, Tsuchida S, Ohmoto T (2014) Neuroradialogy. 36: 308-310.

10. American Brain Tumor Association. Available from: http://www.abta.org/brain-tumortreatment/treatments/surgery.html?referrer=https://www.google.iq/

11. Alturki A, Gagnon B, Petrecca K, Scott SC, Nadeau L, et al. (2014) Patterns of care at end of life for people with primary intracranial tumors. J Neurooncol 117: 103-115. [Crossref]

Copyright: (C2019 Saeed HR. This is an open-access article distributed under the terms of the Creative Commons Attribution License, which permits unrestricted use, distribution, and reproduction in any medium, provided the original author and source are credited. 